\title{
Os Regimes Militares no Brasil e na América do Sul - Historiografia e Perspectivas
}

\section{The military regimes in Brazil and in South America - historiography and perspectives}

\author{
Ozias Paese Neves ${ }^{1}$ \\ Vinícius Liebel ${ }^{2}$
}

\begin{abstract}
Resumo
O objetivo deste paper é abordar o estado da arte na historiografia dos regimes ditatoriais sul-americanos das décadas de 1960 a 1980, com ênfase especial sobre a produção e o regime brasileiros. Nesse sentido, são abordadas as principais correntes e temáticas do campo, desde os estudos pioneiros dos brasilianistas Guillermo O’Donnell, Alfred Stepan e Juan Linz até os esforços mais recentes, incentivados pelos aniversários dos golpes militares e pelos eventos e debates que as datas proporcionaram. A memória e a conceitualização dos regimes, seus elementos constituintes, suas vítimas, e os estudos sobre a natureza, as conexões e o legado de cada um deles são questões perenes nos trabalhos historiográficos presentes neste mapeamento. Além disso, a questão presente da Comissão da Verdade brasileira em perspectiva comparada ganha destaque nas reflexões aqui propostas.
\end{abstract}

Palavras-chave: ditaduras militares; violência e memória; Comissão da Verdade; transição democrática.

\begin{abstract}
The purpose of this paper is to discuss the state of the art in the historiography of the South American dictatorships from the 1960s to the 1980s, with special emphasis on the Brazilian regime and historiographical production. In this sense, the main currents and themes of the field are addressed, from the pioneering studies by the brazilianists Guillermo O'Donnell, Alfred Stepan and Juan Linz to the more recent efforts, encouraged by the anniversaries of military coups and the events and discussions which these dates have stimulated. The memory and the conceptualization of the regimes, their constituent elements, their victims, and the studies on the nature, the connections and the legacy of each of them are perennial issues in the historiographical works present in

\footnotetext{
1 Mestre em História. Docente do Departamento de História da Universidade Federal do Paraná (Assistente I-A). Doutorando pela mesma instituição onde desenvolve pesquisa sobre As cartilhas da Constituinte e a transição política no Paraná: memórias, sentimentos e utopias (1985-1988), com financiamento pela Capes. E-mail: ozias.pn@gmail.com.

${ }^{2}$ Professor Colaborador do PPG de História da Pontifícia Universidade Católica do Rio Grande do Sul (PUC-RS) e bolsista PNPD-Capes junto à mesma instituição, onde desenvolve pesquisas com o projeto Humor, Memória e Autoritarismo - Imprensa Ilustrada, Política e Sociedade em Perspectiva Político Cultural. E-mail: v.liebel@uol.com.br.
}

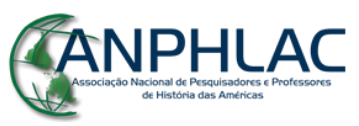

Revista Eletrônica da ANPHLAC, ISSN 1679-1061, № . 18, p. 56-86, jan./jul. 2015.

http://revista.anphlac.org.br/ 
this overview. In addition, the issue of the Brazilian Truth Commission in comparative perspective is highlighted in the here proposed reflections.

Keywords: military dictatorships; violence and memory; Truth Commission and democratic transition.

Artigo recebido em: 15 de janeiro de 2015

Artigo aprovado para publicação em: 15 de abril de 2015

\section{Introdução}

Tema corrente em 2014, ano em que se completou o cinquentenário do golpe militar no Brasil, as ditaduras que se impuseram, especialmente no Cone-sul, nas décadas de 60 e 70 (exceção feita ao Paraguai, que sofrera o golpe em 1954), compõem algumas das páginas mais sombrias da história de nossa região. Elas são lembradas nos inúmeros eventos universitários e nos resultados que a Comissão Nacional da Verdade publicou ${ }^{3}$, em um processo de disputa de memórias outrora silenciadas. Antes, porém, como lembrou Manuel António Garretón em um desses eventos ${ }^{4}$, a eleição presidencial chilena de 2013 já havia reavivado o tema, quando Michelle Bachelet, filha de Alberto Bachelet (brigadeiro membro do governo de Salvador Allende), enfrentou Evelyn Matthei, filha de Fernando Matthei (membro do governo de Pinochet). Uma imagem romantizada de justiça histórica ganhou o espaço público chileno quando Bachelet, exatos 40 anos depois do golpe de 11 de setembro, venceu as eleições e se tornou a primeira mulher reeleita no país.

Apesar de serem muitas vezes pensadas em conjunto, as ditaduras militares e as transições políticas na América Latina estão longe de ter uma unidade, como os estudos recentes podem comprovar. Tanto em duração quanto em formação e modus operandi,

\footnotetext{
${ }^{3}$ O relatório final da Comissão Nacional da Verdade foi divulgado em 10.12.2014, está disponível no site http://www.cnv.gov.br/index.php/outros-destaques/574-conheca-e-acesse-o-relatorio-final-da-cnv.

${ }^{4}$ Fala de Garretón (Univ. de Chile) na Mesa Redonda Propaganda, Repressão e Resistência na América Latina, no Simpósio Internacional O Golpe de 1964 e a Onda Autoritária na América Latina, realizado na Universidade de São Paulo (USP) entre 24 e 27 de março de 2014.
}

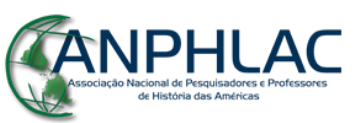

Revista Eletrônica da ANPHLAC, ISSN 1679-1061, №. 18, p. 56-86, jan./jul. 2015.

http://revista.anphlac.org.br/ 
os regimes militares se distinguem por particularidades que ultrapassam aspectos meramente nacionais e geográficos. Esforços para compreendê-las de forma conceitual e coerente, entretanto, alocando-as em uma categoria específica de regime autoritário, não faltaram. Historiadores e cientistas políticos promoveram tais esforços em uma tentativa de análise comparativa, ao menos em um primeiro momento, com outros regimes não democráticos na história, em especial no século XX. A produção historiográfica daí resultante é vasta, e dificilmente poderia ser resumida em um artigo de poucas páginas. Este texto, dessa forma, se propõe traçar um panorama amplo desse campo de produção, trabalhos de relevância em seu decorrer e algumas de suas controvérsias. Não se propõe, é claro, a ser uma revisão definitiva, mas sim a prover uma revisão do estado da arte, dando conta de um mapeamento necessário da produção no tema das ditaduras e transições do Cone sul, com foco especial no Brasil, e , a um só tempo, de introdução e arrolamento dos trabalhos sobre a temática.

\section{Debates historiográficos sobre os regimes militares}

Os primeiros resultados de relevo nesse âmbito, e ainda hoje relevantes nas discussões historiográficas, são os trabalhos de Alfred Stepan (1971, 1973 e 1980), Guilhermo O’Donnell (1973 e 1987) e Juan Linz (1973, 2000). Os esforços desses autores apontam para a caracterização dos regimes militares latino-americanos, em especial os sul-americanos, como regimes militares tecnocrático-burocráticoautoritários. Essa denominação é derivada, em primeiro lugar, da condição repressiva dos regimes impostos, proveniente principalmente do combate a ideologias de caráter socialista e/ou populista. Esse caráter permanentemente combativo da cúpula dirigente tem suas origens em dois campos discursivos: um histórico nacional e outro conjuntural internacional. O campo histórico nacional se refere ao enfraquecimento estrutural do modelo populista e nacional-desenvolvimentista (que aumentou a industrialização e urbanização dos países em um primeiro momento, modificando o cenário político e econômico dos países, mas cujo desenvolvimento se mostrava cada vez mais insustentável e dependente do capital internacional), coligado à radicalização de seus discursos em direção às políticas de socialização e ao aumento da participação política

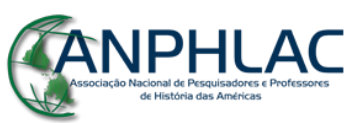

Revista Eletrônica da ANPHLAC, ISSN 1679-1061, №. 18, p. 56-86, jan./jul. 2015.

http://revista.anphlac.org.br/ 
da base econômico-social da população. Segundo Boschi (1979, p. 99), os empresários industriais só haviam favorecido o rótulo do nacionalismo "progressista" até o ponto em que prevalecia o interesse por conquistar um espaço na comunidade internacional, desta forma atraindo os investimentos estrangeiros. Assim, retiraram seu apoio à aliança populista alinhando-se com os militares, cuja noção de nacionalismo equacionado à segurança nacional acabaria por favorecer um projeto de crescimento econômico a todo custo. No campo conjuntural internacional, o posicionamento desses países na nova ordem da Guerra Fria e a eclosão da Revolução Cubana causaram certa "pressão psicológica" sobre a elite, que viu nos militares o grupo perfeito para coordenar a moderação desse novo momento (STEPAN, 1971, p. 64). Pensando o caso brasileiro, João Quartim de Moraes diverge desta análise de Stepan, sugerindo que ela é fruto de uma analogia equivocada da função política exercida pelo imperador e que teria sido assumida pelos militares ao término do regime monárquico. Para esse autor, "a doutrina do poder moderador serve, neste sentido, para justificar a permanência da presença das Forças Armadas na política não mais com a função dirigente que assumiram em 1964, mas como último recurso da ordem burguesa e, portanto, como solução de força para as situações de crise de hegemonia" (MORAES, 2001, p. 108).

Parte da historiografia tradicional enfocava o cenário global de crise política na esfera civil, que levaria um grupo organizado, no caso os militares, a surgir como alternativa sólida à crise de autoridade e de legitimidade da arena política, possibilitando o surgimento de um regime de moldes pretorianos, conforme análises de Huntington (1964). A tese do pretorianismo, entretanto, tem sido colocada em xeque pelas pesquisas mais recentes, que apontam para a forte participação de diferentes ramos da sociedade civil na ascensão e manutenção dos militares no poder, levando à definição mais corrente de ditadura civil-militar (ROLLEMBERG, 2003). Por outro lado, a própria noção de populismo tem sido matizada por estudos que percebem uma experiência democrática no Brasil entre 1946 e 1964. Nesse sentido, Jorge Ferreira reconhece que, apesar da repressão aos comunistas e ao movimento sindical, das tentativas de golpe em 1954, 1955 e 1961, presidentes foram eleitos, houve alternância de poder e a bandeira da democracia e da legalidade encontrava-se nas mãos da esquerda durante todo o período. Isso implicou seguidas vitórias sobre a direita golpista,

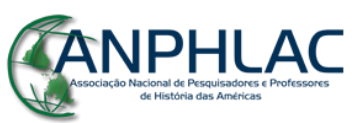

Revista Eletrônica da ANPHLAC, ISSN 1679-1061, №. 18, p. 56-86, jan./jul. 2015.

http://revista.anphlac.org.br/ 
cenário alterado somente em março de 1964, quando a esquerda, no afã de “implementar as reformas a qualquer preço, na 'lei ou na marra', passou a denunciar o regime democrático, sobretudo o conservadorismo do Congresso Nacional, como um empecilho para viabilizar o conjunto de mudanças que exigiam, sobretudo a reforma agrária" (FERREIRA, 2003, p. 339). Tal perspectiva, entretanto, dificilmente pode ser aplicada diretamente aos demais países da região, podendo encontrar alguma ressonância apenas com o caso chileno e sua "ditadura tardia". Nesse sentido ainda, pesquisas da última década têm também sublinhado o papel dos EUA e sua política de matiz anticomunista na instauração dos golpes militares e na manutenção dos regimes, ao menos em um primeiro momento. Mais uma vez, o caso do Brasil e da Operação Brother Sam é emblemático (FICO, 2008, GREEN, 2009).

A caracterização tecnocrático-burocrática nas pesquisas clássicas acima mencionadas se refere à natureza do trabalho e da máquina que sustentava o regime. Em todos os casos, a falta de uma ideologia coesa, ou melhor, a heterogeneidade ideológica dos militares (CODATO, 2004, p. 30) era compensada por uma busca da excelência técnica, sendo os principais ramos da administração conduzidos por funcionários de carreira (tanto no Estado quanto no Exército ou em empresas privadas), em um reflexo da própria estrutura de comando e de avanço de carreira do Exército. É também com base nessa tecnocracia que se sustenta a despolitização do Estado e o fechamento da vida política aos setores populares. Pretendia-se reduzir as questões sociais e políticas a questões "técnicas", a se resolverem mediante interações entre as cúpulas das grandes organizações acima mencionadas (O’DONNELL, 1987, p. 21). As questões administrativas estavam, assim, ligadas principalmente ao aparato burocrático, selecionado em termos tecnocratas, afastando-se a política e as vozes dissonantes e minoritárias dos canais de comunicação e decisão (LINZ, 2000, p. 195-6). Essa estrutura fez com que os regimes autoritários se mostrassem, de acordo com O’Donnell (1987, p. 21), "uma etapa de transformações nos mecanismos de acumulação das suas sociedades, que por sua vez formam parte de um processo de 'aprofundamento' de um capitalismo periférico e dependente, mas dotado de uma extensa industrialização."

Os trabalhos clássicos de caracterização dos regimes autoritários na América Latina contam com herdeiros, especialmente no campo dos estudos de História e

\section{GANPHLAC}


Ciência Política comparadas. Em esforços por uma teoria dos motivos das ascensões e quedas das ditaduras, vários elementos têm sido tomados para análise. Nos planos internos e em perspectivas estruturais, culturais e conjunturais, os estudos das elites, dos partidos, dos atores políticos, das classes econômico-sociais e dos militares ganham relevância. Tais variáveis surgem como peças de um quebra-cabeças interno, onde cada país que sofreu com uma ditadura nas décadas de 60 e 70 apresenta dinâmicas próprias específicas, ainda que por vezes semelhantes. Tomados no conjunto, entretanto, as ditaduras tendem a ser analisadas como o resultado de uma "onda" autoritária (que teria sido seguida por outra onda, desta vez democrática, no modelo sugerido por Huntington [1993]). Os fatores que levam a essas ondas são ainda motivo de debate e de análise, mas a literatura aponta para uma preponderância de aspectos externos, como políticas imperialistas, políticas pelos direitos humanos, grau de estabilidade dos países vizinhos, o momento da Guerra Fria, atores e agências internacionais, conjunturas exteriores, etc. (MAINWARING e PÉREZ-LIÑÁN, 2014). Na historiografia recente, o trabalho de James Green (2005) sobre o caso brasileiro pode ser apontado como um exemplo que se aproxima dessa vertente, localizando na mudança de olhar da política externa norteamericana em direção aos direitos humanos, durante o governo Carter, um ponto esclarecedor para o recrudescimento da ditadura. Essa aproximação explicativa dos fatores externos nega, entretanto, a teoria da modernização, que prega uma percepção evolutiva determinista, ligando o desenvolvimento econômico ao crescimento dos valores democráticos (LIPSET, 1959).

Mas, apesar dessas definições coerentes e unificadoras, as ditaduras devem ser ainda analisadas tipologicamente e, desta forma, distinguidas. As análises comparativas aqui descritas se baseiam em uma compreensão aproximada das estruturas de poder que as norteiam, baseada principalmente em O’Donnell (1973 e 1987), mas evidenciam características específicas no que tange a vivência, a busca pela legitimação e a perpetuação dos regimes. É nesse percurso que os estudos transnacionais reafirmam seu espaço, principalmente na historiografia dos últimos dez anos.

Nesse sentido, algumas discussões podem ser citadas como exemplares da interação teórica e analítica nos estudos de cada caso específico. O trabalho de Pilar Calveiro, por exemplo, abriu caminho para uma reflexão transnacional a respeito do

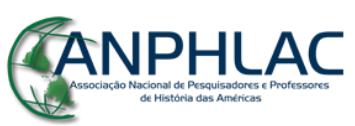

Revista Eletrônica da ANPHLAC, ISSN 1679-1061, №. 18, p. 56-86, jan./jul. 2015. http://revista.anphlac.org.br/ 
princípio propulsor do poder nas ditaduras. Em seu estudo privilegiado, Calveiro argumenta por um "poder desaparecedor" (CALVEIRO, 2013, p. 40), localizando o desaparecimento político de cidadãos na sociedade argentina ditatorial como, a um só tempo, sua característica mais marcante e seu princípio de ação. É a partir do ambiente que tais desaparecimentos provocam, da aura de terror diante da aleatoriedade dos sequestros e desaparecimentos, que o próprio poder dos militares se edifica e que a sociedade a eles se curva. Essa reflexão levou Janaína de Almeida Teles a pensar, em termos análogos, a ditadura brasileira. Nela, não eram os desaparecimentos que pautavam o poder ditatorial, mas sim a tortura. Dessa forma, Teles $(2013$, p. 8) aponta para um poder torturador na base da dinâmica ditatorial brasileira como o princípio de ação do regime dos generais. A tortura, enquanto elemento estrutural e princípio de ação da ditadura brasileira, tem no estudo de Mariana Joffily (2008) um mapeamento da estrutura interna dos DOI-CODI, seu modus operandi interrogatório e mesmo sua historicização, localizando seus primórdios na Operação Bandeirante, em um estudo consistente do "centro das engrenagens" do regime brasileiro. Já Enrique Padrós, em seus estudos acerca da ditadura uruguaia (2005, p. 539 et seq.), aponta o caminho para a percepção de um poder enlouquecedor nesse regime, cuja insistência em manter seus presos vivos, ao contrário de argentinos (que se pautavam no desaparecimento) e chilenos (que recorriam ao fuzilamento), implicou uma política de tortura durante o gran encierro, que tinha como objetivo expresso a fragilização mental e psicológica permanente de seus presos. Essa política estaria ancorada na tradição cultural democrática uruguaia, que não aceitaria a morte simples de presos políticos (PADRÓS, 2012). O enlouquecimento seria, assim, a saída e justificativa dos militares para, ao mesmo tempo, instituir e negar a repressão. Já Anthony W. Pereira analisa o autoritarismo e o estado de direito no Brasil, no Chile e na Argentina procurando apreender as diferenças na maneira como fazem uso da lei para punir opositores e dissidentes, desde um nível relativamente elevado de cooperação entre o poder Militar e o Judiciário no Brasil, passando pela usurpação da autoridade da lei pelos militares no Chile, até a negligência completa do judiciário por parte dos militares argentinos (PEREIRA, 2010, p. 26), o que trará também repercussões nos modelos de transição política e justiça de transição, como abordaremos adiante.

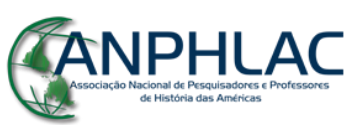

Revista Eletrônica da ANPHLAC, ISSN 1679-1061, №. 18, p. 56-86, jan./jul. 2015. http://revista.anphlac.org.br/ 
Outra aproximação dos diferentes casos de ditaduras na América pode ser feita através da pesquisa sobre a constituição dos golpes, na qual o mecanismo do pretorianismo (HUNTINGTON, 1964) aparece como base para as análises. É dessa forma que as reflexões de Marcos Napolitano (2014) apontam para um golpe civilmilitar no Brasil, coincidindo com a grande maioria dos estudos sobre o tema (p. ex. ROLLEMBERG 2010; REIS 2014), mas se distanciando na definição mais corrente na atualidade de regime civil-militar (REIS, 2014, p. 21 e FERREIRA, 2014, p. 333). Para Napolitano, o regime seria estritamente militar, com o centro de decisões se afastando cada vez mais do campo civil, ainda que este lhe desse respaldo e apoio. Uma linha semelhante pode ser visualizada na competente reconstrução do movimento estudantil por Samantha Quadrat (2010), que toma o campo da juventude como um microcosmo da sociedade chilena e expõe a falência do diálogo entre as instituições políticas civis e o rápido processo de ingovernabilidade que as elites e os setores conservadores da sociedade chilena causariam no combate à "via pacífica rumo ao socialismo", o que acaba proporcionando o vácuo de autoridade que, como nos demais casos, seria preenchido pelo Exército. O padrão dessa grande narrativa de confrontação, desestabilização e ascensão da alternativa militar se repete também nos estudos dos casos do Paraguai (LEWIS, p. 200 et seq.), Argentina (TORRE E LIZ, p. 125 et seq.) e Uruguai (FINCH, p. 174 et. seq.; PADRÓS, 2005).

Estudos mostram também a convergência das operações das ditaduras no que tange à repressão fora de seus limites. Um dos primeiros frutos das pesquisas nos arquivos dos regimes militares no Cone-sul foi a descoberta da Operação Condor, uma rede coordenada de informação que reunia os serviços de inteligência das principais ditaduras do período na região: Chile, Argentina, Brasil, Paraguai, Uruguai, Bolívia e, posteriormente, Equador e Peru. A rede e suas ações, apesar de serem oficializadas em 1975 em reunião ocorrida em Santiago, já eram uma realidade ainda no final da década de 60 (MCSHERRY, 2002, p. 38). Mesmo antes de algumas das ditaduras virem à tona, grupos militares de diferentes países iam ao Brasil para aprender "técnicas de interrogatório" e métodos de repressão, em uma complementação do que era passado na Escola das Américas. Samantha Quadrat (2006) aponta para as formas de ação da rede, que não apenas trocava informações sobre os eleitos subversivos, mas também

\section{GANPHLAC}


deslocava os prisioneiros e procurados sem a necessária burocracia e registros de transferência. Em múltiplas formas, a Operação Condor funcionou como um facilitador da repressão, guiada pela supressão do pensamento comunista e revolucionário (especialmente após a criação da Junta de Coordenação Revolucionária) em suas fronteiras e pelo princípio da cooperação internacional. Mas, apesar do forte apelo anticomunista, não apenas aqueles ligados à ideologia eram visados. Qualquer opositor dos governos passa a ser alvo da operação, líderes democratas e liberais entre eles. São exemplos do alcance dessa perseguição o presidente brasileiro João Goulart, morto na Argentina, e Orlando Letelier, político e embaixador chileno morto em Washington. A ditadura chilena, nesse sentido, foi a mais audaciosa, levando sua perseguição a solo norte-americano e europeu (DINGES, p. 37 et. seq.). A extensão das ações repressivas, além de ser potencializada pela cooperação, mostra que os órgãos repressores não conheciam limites territoriais.

As reflexões sobre as esquerdas no período são também preocupações de historiadores e cientistas políticos. Motivados por diferentes pontos de vista e ancorados em diferentes tradições, os intelectuais que focam as ações da esquerda, especialmente a armada, propõem hoje reflexões que mexem com o imaginário político dessas sociedades, especialmente com a memória das esquerdas que se construiu nos anos das ditaduras. Nesse sentido, Denise Rollemberg (2003) aponta para a natureza autoritária do pensamento dessa esquerda revolucionária ao afirmar que "as esquerdas revolucionárias dos anos 1960 e 1970, como de resto a sociedade, inseridas nestas referências e tradições, não tinham a democracia como um valor supremo. A democracia era burguesa, liberal, parte de um sistema que se queria derrubar". Evidenciando essa "semente autoritária" ainda no momento anterior ao golpe, a historiadora intenta demonstrar que a sociedade, face a dois projetos autoritários, escolheu não apoiar o projeto das esquerdas, isolando-as na resistência. Partiria daí a semente para o imaginário da resistência isolada e democrática, uma imagem envolta em mistificações, que serviria à sua própria memória das esquerdas (RIDENTI, 2004). Tal concepção é criticada por Caio Navarro Toledo, que enxerga um certo revisionismo e o retorno da tese dos dois demônios ao imputar um caráter autoritário ao projeto das esquerdas. Para Toledo, tratava-se de ampliar a noção de democracia política para além

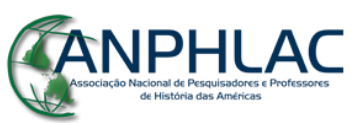

Revista Eletrônica da ANPHLAC, ISSN 1679-1061, №. 18, p. 56-86, jan./jul. 2015.

http://revista.anphlac.org.br/ 
da mera pauta burguesa a partir da realização de profundas reformas da ordem capitalista no Brasil (TOLEDO, 2004, p. 22). Na Argentina, seguindo os mesmos passos, Claudia Hilb (2013) se interroga sobre a responsabilidade das esquerdas armadas pelas fraturas da sociedade argentina, sobre os sentidos da violência e seu lugar na construção de sentimentos de pertencimento a um grupo e de plenitude identitária. Hilb coloca a questão premente da memória e do lugar desse "heroísmo" no imaginário da sociedade e da esquerda, bem como nas concepções atuais sobre a política e o fazer político, seguindo os resquícios desse ímpeto autoritário e violento. O intento da cientista política, ela mesma uma militante de esquerda nos anos 70, é refletir sobre esse ponto sangrento da história das esquerdas progressistas argentinas e pensar seu lugar nos esforços atuais por uma política democrática, social e não violenta. A dificuldade das esquerdas em lidar com seu próprio passado é também levantada, em cores revisionistas, por Marco Antônio Villa (2014), em uma cruzada pessoal em busca da responsabilização das esquerdas pelo endurecimento dos militares em 1968, ano em que, segundo o autor, é possível finalmente falar em uma ditadura "à brasileira", seguindo a linha que ficou popularmente conhecida como da "ditabranda" (Folha de São Paulo, 2009).

No que tange às especificidades do caso brasileiro e, principalmente, às discussões historiográficas em torno do tema (NAPOLITANO, 2011; Fico, 2004), as análises mostram uma variação constante nas ações dos generais. A tradicional leitura que aponta a existência de dois grupos - o Castelista e a Linha dura - (SKIDMORE, 1988 ) é complexificada a partir da tese de João Roberto Martins Filho (1995, p. 114), para quem os militares poderiam ser divididos em quatro grupos: a) castelistas ligados a Castelo Branco e à Escola Superior de Guerra; b) a linha dura, da qual se teria valido Costa e Silva para 'emparedar' Castelo na eleição de 1966, mas que era composto por militares de menor patente com certa dificuldade de se organizar hierarquicamente; c) o grupo albuquerquista, de seguidores ligados ao gen. Affonso de Albuquerque Lima, portadores de um nacionalismo militar mais articulado; d) grupo em torno do comandante do exército Costa e Silva. Para Martins Filho, os militares que encontravam divergências na forma de atuar e compreender os rumos da instauração da revolução tinham alguns aspectos concordantes, mantendo a unidade apenas na oposição ao

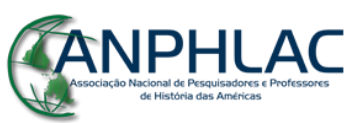

Revista Eletrônica da ANPHLAC, ISSN 1679-1061, №. 18, p. 56-86, jan./jul. 2015. http://revista.anphlac.org.br/ 
comunismo e nas políticas essencialmente elitistas, que barravam as possibilidades de ganho político e econômico dos demais grupos sociais. "Estes dois princípios conviviam com a obsessão pelo desenvolvimento industrial e superação do subdesenvolvimento de forma associada ao capital multinacional, criando um ambiente de segurança e desenvolvimento" (NAPOLITANO, 2011, p. 210).

Mas se essa orientação estrutural do regime é tida como ponto pacífico, o mesmo não se pode falar de outros temas. A natureza do golpe e a interpretação que se dá ao momento imediatamente anterior, por exemplo, são ainda alvos de grandes discussões. Em que pese a importância da produção das décadas de 60 e 70 (que, como apontado anteriormente, buscavam um entendimento conceitual do golpe e suas origens, bem como a produção de relatos memorialistas e as explicações teóricas marxistas, que apontam para a estrutura econômica e de produção na raiz dos conflitos sociopolíticos e para o golpe como ação preventiva da burguesia em resposta ao afunilamento da luta de classes), nas décadas de 80 e 90 começam a surgir estudos que se colocam de forma crítica às leituras estruturalistas e marxistas. Essa nova linha de produção historiográfica, baseada nos princípios da Nova História (Cultural e Política), busca uma reinterpretação dos eventos à luz dos elementos culturais, das dinâmicas próprias da política e mesmo da posição do indivíduo e dos grupos em relação à mentalidade e aos sentimentos.

A luta da elite burguesa - civil, portanto - pela hegemonia política, apoiada em uma ampla conspiração e em estudos sobre a realidade brasileira, é o tema de estudo de René Dreifuss (1981). Baseado nas ações e documentos produzidos pelos Institutos de Pesquisas Sociais e de Ação Democrática, o trabalho de Dreifuss tem a virtude de colocar os empresários e a elite civil no centro da interpretação do golpe, o que resulta na hoje em geral aceita tese do golpe civil-militar (ainda que a natureza do regime, como já tratado, ainda permaneça em discussão). Em uma linha próxima, Alfred Stepan (1971) já havia apontado, em um trabalho funcionalista ligado à escola da rational choice, a tese de uma conspiração militar guiada por uma orquestração racional de decisões pautada, em grande medida, pela Escola Superior de Guerra (sem esquecer das diferentes linhas de pensamento no interior da mesma). Nilson Borges Filho aproxima a ESG da norte-americana National War College, que tratou de difundir entre as elites

\section{GANPHLAC}

Revista Eletrônica da ANPHLAC, ISSN 1679-1061, № 18, p. 56-86, jan./jul. 2015. 
uma ideologia própria, voltada para uma concepção bastante específica dos problemas pertinentes ao desenvolvimento econômico e das instituições políticas internas e externas para o Brasil (BORGES, p. 52-3). Ainda entre as teses explicativas para a ascensão dos militares, a da falta de governabilidade do governo Jango, causada por uma paralisia decisória que apresentaria os militares como alternativa de ordem, é defendida por Wanderley Guilherme dos Santos (2003). Em sua visão, ideologias, conflitos sociais ou materiais estão fora da equação, que se pauta em uma constatação puramente política da falência decisória. A incapacidade de Goulart em levar adiante suas reformas e a igual incapacidade da oposição em se apresentar como alternativa viável, ou seja, as posições antagônicas radicalizadas, seriam a causa da inércia em que o governo se encontrava e, portanto, a causa da violência eclodida, ou, nas palavras do autor, na "mácula na ordem jurídica" (SANTOS, 2003, p. 19) em que se constituiu a intervenção militar.

Tais interpretações se mesclam nos múltiplos estudos contemporâneos que tendem a centralizar o papel dos atores e instituições civis no golpe e nas ações do regime, seja de forma ativa ou em conivência. A ideia do golpe e do regime civilmilitares é, hoje, uma tendência, ainda que não unanimidade. Da mesma forma, a transformação do golpe em regime é outro ponto de conflito nas interpretações historiográficas. Para além da análise dos Atos Institucionais (especialmente o 2 e o 5) como fatores de radicalização e de imposição de uma nova ordem (CODATO, 2004), a semântica do poder (CHIRIO, 2007), a mitologia castelista e as interações no interior da classe militar (CHIRIO, 2012) também concorrem como elementos de reflexão nas análises do processo. São dignos de nota, ainda, os esforços de João Roberto Martins Filho, que trata da cizânia militar enquanto fator de dinâmica e crises do regime (MARTINS FILHO, 1995).

As décadas de 90 e de 2000 trouxeram a ampliação, através da Nova História, de pesquisas de temas e personagens negligenciados até então. É o caso, por exemplo, de Maria Celina D’Araújo e Gláucio Soares (1994-5) e Celso Castro (2002), que buscam as vozes dos militares e mostram a mentalidade que cobria tal grupo por ocasião do golpe e do regime militar. As variações de pensamentos no interior da classe militar são evidenciadas, bem como sua memória própria, na qual uma mitologia em redor de uma

\section{CANPHLAC}

Revista Eletrônica da ANPHLAC, ISSN 1679-1061, №. 18, p. 56-86, jan./jul. 2015.

http://revista.anphlac.org.br/ 
suposta ação heroica pelo salvamento da nação encontra lugar central. A renovação de enfoques e de perspectivas segue com a renovação historiográfica pela História Conceitual do Político (ROSANVALON, 1995) e pela História Cultural da Política (MERGEL, 2014), que encontram em objetos e manifestações culturais um plano privilegiado para estudar e compreender as dinâmicas sociais do período. É o caso das obras, por exemplo, de Rodrigo Patto Sá Motta e Marcos Napolitano. O primeiro, pesquisando a cultura política comunista (2013) e anticomunista (2002) no país, foi capaz de mapear as diferentes comunidades de sentido que compuseram o espectro social acerca do tema, uma contribuição inestimável para reconhecer e compreender os posicionamentos e as visões de mundo que daí advieram. Motta também acrescentou ao debate sobre o golpe uma análise das charges publicadas na grande mídia brasileira que retratavam Jango e o jogo de poderes pré-1964 (2006) e que apontam para a centralidade da temática da esquerda nas críticas humorísticas ao presidente. A inserção de fontes pictóricas, em especial as charges, ao debate historiográfico ainda é um expediente inovador, no que o estudo do autor se destaca. Por fim, em sua mais recente obra, o historiador examina a dinâmica universitária brasileira no período (2014), vislumbrando a lei da acomodação, antes da adesão completa ou da resistência, como a norma nos campi, tema retratado pela Associação de Docentes da USP no chamado Livro Negro da USP (1979). Napolitano, ao pesquisar a música popular brasileira no período militar (2001), não apenas apontou questões pertinentes acerca da indústria da música no Brasil e de certa permissividade da ditadura com este setor, o que poderia apontar para um projeto modernizante conjugado com um regime conservador, mas também que a MPB, exaltada muitas vezes por sua canção de protesto, é, na verdade, guiada por uma sublimação da violência e para uma catarse da repressão autoritária. A canção de protesto ou de barricada, que buscaria um rompimento estético-lírico com a produção popular brasileira e que seria primariamente representada por Geraldo Vandré, não se desenvolve. Dessa forma, a música não atinge o plano da ação política de resistência, arranhando apenas o plano da conscientização.

Essas novas tendências e debates na historiografia brasileira vêm modificando a memória do período, construindo novas percepções e destruindo alguns dos mitos que ainda persistem. Alguns silenciamentos sobre o período e perseguições a grupos

\section{CANPHLAC}


específicos, como os homossexuais, tornam-se novos objetos de investigação, como no recente trabalho Ditadura e Homossexualidades, de James Green (2014), que visa discutir como a ditadura lançou dificuldades, tanto aos modos de vida de gays, lésbicas e pessoas trans quanto à própria afirmação do movimento LGBT no Brasil ao longo dos anos 60,70 e 80 .

\section{As transições políticas - perspectivas e debates historiográficos}

As investigações sobre os processos de transição política constituíram-se como objeto de pesquisa antes mesmo do término de muitos regimes ditatoriais na América Latina. Alguns trabalhos pioneiros foram realizados fora dos próprios países de origem pelo acesso privilegiado a fontes, na época negadas aos pesquisadores locais. Nesses casos, destacam-se as investigações no campo da Ciência Política, em especial aquelas ligadas à linha do Institucionalismo Histórico.

$\mathrm{O}$ argentino Guilhermo O’Donnell, por exemplo, desenvolveu um modelo explicativo a partir da compreensão de duas formas clássicas de transição "uma, rápida, com forte ruptura com o autoritarismo vigente, denominada transição por colapso; outra, lenta e gradual, segura pelas forças até então no poder, fruto de acordo entre os setores conservadores no poder e as forças moderadas na oposição" (SILVA, 2003, p. 273). A última, denominada transição pactuada, pôde ser observada no Brasil, enquanto a transição por colapso teria como principal exemplo a Argentina. Em 1986, Alfred Stepan situou a consolidação da democracia na América Latina na dependência de uma série de fatores, como o fortalecimento dos partidos políticos, a crise mundial da dívida externa e a habilidade política para colocar a democracia como suporte da transição (STEPAN, 1986, p. 81). Em 1999, Stepan publicou, juntamente com Juan Linz, outra obra dando enfoque à variável da economia política da legitimidade, com o privilégio de setores civis autorizados (como os partidos políticos) desenvolverem uma participação no processo de transição. Resultou também numa tipologia sobre a legitimidade e eficácia dos regimes democráticos (LINS e STEPAN, 1999, p. 266). Evidentemente não faltaram trabalhos fundados em uma perspectiva erudita, porém tradicional, da História Política, bem exemplificado pelas obras de Thomas Skidmore (1988 e 1994).

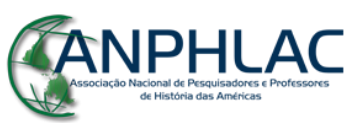

Revista Eletrônica da ANPHLAC, ISSN 1679-1061, №. 18, p. 56-86, jan./jul. 2015.

http://revista.anphlac.org.br/ 
Segundo Adriano Codato (2005, p. 83), essa primeira leva de trabalhos inaugurou a transitologia constituída por três características: a) ênfase nos atores políticos, seus interesses, valores e estratégias; b) destaque para valores endógenos de cada país; 3) adoção de conceituo minimalista de democracia, à la Schumpeter, pelo modo de seleção de lideranças. A problemática dos elementos caracterizadores da transitologia levou ao debate, principalmente nos casos de transição pactuada, sobre a diacronia dos regimes autoritários. Não é mais suficiente a caracterização dos termos iniciais e finais das ditaduras (1964-1985, para o caso da ditadura brasileira): torna-se necessário caracterizar as nuances e tensões internas do regime, pensar sobre os graus de violência institucionais agregados e naqueles que persistem durante os processos de democratização.

Evidentemente, tal verticalização fez com que os consensos sobre a cronologia do regime ficassem bastante turvados. No caso brasileiro, Daniel Aarão Reis (2014) centra a caracterização da ditadura entre 1968 e 1979, reconhecendo prenúncios e resquícios autoritários desde a gênese da ditadura (1961-1964), bem como uma graduação da violência autoritária, desde a tensão entre democracia e ditadura (19641968), passando pelos anos de chumbo (1968-1974), até a nova institucionalização da ditadura (1974-1979) e, finalmente, a transição democrática (1979-1988). Por sua vez, Maria Helena Moreira Alves aponta ciclos de liberalização e de repressão dentro de cada etapa da ditadura ao enfocar o Estado e oposição no Brasil entre 1964-1984 (ALVES, 2005). Fundado no pensamento da Ciência Política, Adriano Codato propõe uma análise institucional na definição das temporalidades da ditadura. Em sua periodização, os governos de Castello Branco e Costa e Silva representariam a constituição do regime político ditatorial-militar, entre Costa e Silva e Médici se daria a consolidação, no governo Geisel teríamos a transformação do regime, o período de Figueiredo marcaria a desagregação da ditadura militar, enquanto a era Sarney sintetizaria a transição, sob tutela militar, para o regime liberal-democrático. Por fim, a consolidação do regime liberal-democrático dar-se-ia apenas nos governos Collor, Itamar Franco e Fernando Henrique Cardoso (CODATO, 2005, p. 87).

Essa problematização sobre o término da ditadura e as zonas de persistência de elementos de exceção remetem ao tema do controle da transição. Para além da análise

\section{GANPHLAC}


conjuntural-internacional de plano macro-internacionalistas, a historiografia passou a questionar a construção social dos regimes autoritários (QUADRAT e ROLLEMBERG, 2010) e problematizar uma díade sobre a transição: o movimento de abertura coube estritamente aos militares ou teve impulso em movimentos populares? Denise Rollemberg, ao analisar a historiografia da transição brasileira, situa três linhas explicativas para o tema. A primeira enfatizaria o papel dos movimentos sociais de oposição e/ou resistência democrática, que teriam sido decisivos na chamada crise da ditadura e na volta dos militares aos quartéis, vinculados ainda à insatisfação com o fim do milagre econômico. Na segunda, mais complexa e sofisticada, a abertura não teria sido pensada face à crise do milagre, mas, ao contrário, devido ao seu sucesso, procurando-se compreender melhor a alternância entre linha moderada e linha dura, valorizando-se a segunda em seus estudos e localizando no movimento do $\mathrm{ABC}$, em 1978, a derradeira perda do controle pela ditadura. Por fim, a terceira linha interpretativa vê os movimentos de oposição atuando em todo o período, centrando a explicação nos conflitos da própria corporação militar. Os militares jamais teriam perdido o controle; o processo, o ritmo, é dado por tais disputas internas. O governo civil garantiria o não revanchismo. A lei de anistia seria a vitória do governo. Para Denise Rollemberg, na memória coletiva, a primeira linha venceu, deixando-se de lado a questão da sustentação do regime.

O processo de abertura iniciado no governo Geisel sintetizaria a memória construída sobre o regime militar, e 1979 marcaria o sentido de conciliação, da transição para a democracia entre o perdão e o esquecimento. "A partir dali, a sociedade construía a imagem de si mesma como essencialmente democrática, que repudiara o arbítrio, desde o início, desde sempre, numa luta intransigente contra os militares. Na verdade, o golpe tinha sido militar; a ditadura, militar; o regime, imposto; a sociedade, vítima" (ROLLEMBERG, 2010, p. 103). Ela sugere o uso do conceito de zona cinzenta ou o penser double (que serviu para problematizar as tensões da resistência ao regime de Vichy) no misto de apoio e resistência para evitar as mitificações que deixariam de lado a base de sustentação social do regime. Emerge na historiografia um olhar para a sociedade sob os regimes ditatoriais e suas ambivalências, dispondo-se a investigar "como um regime autoritário/uma ditadura obteve apoio e legitimidade na sociedade;

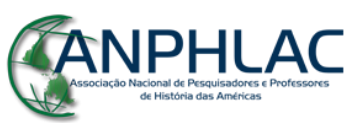

Revista Eletrônica da ANPHLAC, ISSN 1679-1061, №. 18, p. 56-86, jan./jul. 2015. http://revista.anphlac.org.br/ 
como os valores desse regime autoritário/ditatorial estavam presentes na sociedade e, assim, tal regime foi antes resultado da própria construção social" (ROLLEMBERG, 2010, p. 141). No caso argentino, o modelo de O’Donnell encontra ressalvas diante de explicações mais contemporâneas, como as de Ernesto Lopez, que enfatiza a persistência da influência política dos militares durante o regime Alfonsin (LOPEZ, 1994), tocando nos debates sobre as leis do Ponto Final e da Obediência Devida.

O olhar centrado na cultura política autoritária da própria sociedade que permitiu, anuiu e até contribuiu com o regime ditatorial dialoga com outro campo investigativo ao problematizar a continuidade de elementos da ditadura na sociedade e nas instituições de nosso tempo presente (SAFATLE, 2010; PINHEIRO, 2014). O conceito estado de exceção (AGAMBEN, 2004) fundamenta uma série de linhas de pesquisas que procuram debater a persistência, pelo poder político, na desobediência às leis e na transgressão do pacto social dentro da própria democracia, tal como a ação intimidatória dos militares sobre as instituições civis ou do Estado diante da sociedade. Essa historiografia tem apontado práticas de exceção em certos setores através da criminalização dos movimentos sociais, da atuação policial com base na "lei e na ordem", da utilização das Forças Armadas para atuação em áreas de segurança pública (como as Unidades de Polícia Pacificadora - UPPs no Rio de Janeiro) e de um olhar que tende a analisar questões de segurança pública sob as lentes da segurança nacional e, por vezes, do inimigo interno (ZAVERUCHA, 2010, p. 75). A própria validade da noção de transição política é colocada em questão quando se problematizam os silêncios no pós-ditadura, seja o das vítimas e dos sobreviventes da repressão pelo caráter indizível do horror vivido nas salas de tortura, nos campos de fuzilamento do Chile ou de enlouquecimento do Uruguai (PADRÓS, 2012), seja o silêncio de caráter mais geral, de parte da sociedade (indivíduos e instituições) que se nega a falar ou assumir responsabilidade e, com isso, buscar a transformação das instituições remanescentes (TELES, 2009, p. 583; ÁGUILA, 2010, p. 612).

Para lidar com essa zona composta por uma série de permanências autoritárias dos regimes ditatoriais, emergiu o campo interdisciplinar e transnacional da Justiça de Transição. Sua vasta área de atuação inclui desafios para a Ciência Política, o Direito, a História e a memória. Envolve desde a problematização do passado até uma série de

\section{GANPHLAC}

Revista Eletrônica da ANPHLAC, ISSN 1679-1061, №. 18, p. 56-86, jan./jul. 2015. 
políticas de memória para combater os silenciamentos forçados ou voluntários, assim como pretende propiciar o questionamento da validade da legislação autoritária remanescente como leis de segurança nacional, de autoanistia e de imprensa. Também direciona sua atenção para as práticas autoritárias incompatíveis com os regimes democráticos, como a militarização das polícias e a violência policial, a persistência da prática de tortura em delegacias e quartéis, etc. (ZAVERUCHA, 2010, p. 51 e Pinheiro, 2014). Essa intersecção entre as áreas da produção do conhecimento e da ação política geram uma série de desentendimentos e problemas de definição. Glenda Mezarobba (2009, p. 37) define Justiça de Transição a partir da Encyclopedia of Genocide and Crimes against Humanity, como "área de atividade de pesquisa para a maneira como as sociedades lidam com o legado de violações de direitos humanos, atrocidades em massa ou outras formas de trauma social severo, o que inclui genocídio e guerra civil, com vistas à construção de um futuro mais democrático e pacífico”. Trata-se, portanto, de confrontar o passado de abusos como componente de uma estrutura de mudança política. A Justiça de Transição está diretamente ligada à ressignificação dos direitos humanos a partir do contexto do pós Segunda Guerra Mundial.

Alguns autores, como Jon Elster (2004, p. 22), vão além e caracterizam-na como sendo tão antiga quanto a própria democracia ateniense nos embates entre os democratas e os oligarcas; outros, como Ruti Teitel (2003, p. 69), apesar de ressaltar o papel das duas guerras mundiais para uma delimitação de mecanismos transicionais, sugerem que sua consistência tornou-se mais efetiva "nos últimos 25 anos do século $\mathrm{XX}$, com o início dos julgamentos de antigos integrantes das juntas militares, na Grécia, em 1975, e na Argentina em 1983” (MEZAROBBA, 2009, p. 39-40). Suas tarefas são definidas usualmente nos âmbitos das reparações pecuniárias, no exercício do direito de memória coletiva sobre o período (também remetendo a uma reparação de caráter simbólico e identitário), na possibilidade de punições dos responsáveis pelo cometimento de crimes contra a humanidade, derivando em processos judiciais contra os perpetradores do regime, e na retirada do entulho institucional autoritário. É daí que nascem as acusações de revanchismo propagadas pelos militares e seus apoiadores. Entretanto, os direitos, em primeiro lugar, dos parentes de mortos e desaparecidos em saber detalhes do destino dos seus e, em segundo lugar, da sociedade em construir uma

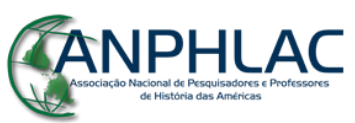

Revista Eletrônica da ANPHLAC, ISSN 1679-1061, №. 18, p. 56-86, jan./jul. 2015. http://revista.anphlac.org.br/ 
memória mais correspondente à violência e aos traumas que sofreu, se mostram imperativos nesse processo de conclusão de uma transição que permanece incompleta.

Nos limites desse artigo não há possibilidade de acompanharmos as inúmeras complexidades e polêmicas da historiografia sobre o processo transicional. Em razão disso, estabelecemos um recorte que direciona o olhar para as diferenças entre os casos argentino e brasileiro. A transição na Argentina deu-se por colapso, o regime militar não resistiu a uma série de insucessos políticos e econômicos, à sua violência interna e, finalmente, ao fracassado projeto de retomar as ilhas Malvinas da Inglaterra. A capacidade de atuação política dos que sofreram as violências do regime acabou gerando uma série de respostas e reações institucionais. A ênfase tem sido na questão da justiça e da busca da responsabilização e punição dos agentes do Estado pelos crimes cometidos durante a ditadura. O caráter pioneiro da Argentina funda-se da noção de "lembrar para não esquecer, para não repetir", assim, "o resgate da memória do que se tinha passado naqueles anos de ditatura revelou-se uma arma de denúncia da repressão e do terrorismo de Estado" (ARAÚJO, 2012, p. 55-56). Transformou-se em instrumento de caráter jurídico para punição dos agentes e uma batalha contra o esquecimento, em que o testemunho tem um caráter central, como no caso da organização Memoria Abierta. Porém, Sarlo (2007, p. 22) destaca que "é mais importante entender do que lembrar, embora para entender também seja preciso lembrar", advertindo para os riscos das contingências do presente e dos usos políticos do passado.

Nesse sentido, Araújo sugere que "nem sempre a reiteração sistemática da lembrança nos leva ao entendimento de um processo histórico" (ARAÚJO, 2012, p. 57). Podemos complexificar a questão ao traçar uma breve consideração sobre os estudos do emblemático caso sul-africano para reconciliação nacional, o Ubuntu. Edson Teles escreveu uma tese comparativa entre as transições do Brasil e do país africano (TELES, 2007), destacando a ascensão de Mandela, em 1994, e como ela tornou possível a criação da Comissão de Reconciliação e Verdade (Truth and Reconciliation Comission). A apuração das violações aos direitos humanos se deu por meio da narrativa das vítimas e da confissão dos responsáveis pelos crimes. No caso africano, haveria troca da punição pela confissão dos crimes. Enquanto a Argentina tem como foco a punição dos responsáveis, o Brasil, a reparação pecuniária das vítimas, a ênfase sul-africana seria a

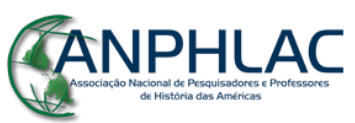

Revista Eletrônica da ANPHLAC, ISSN 1679-1061, №. 18, p. 56-86, jan./jul. 2015. http://revista.anphlac.org.br/ 
reconciliação entre as vítimas e os criminosos (TELES, 2010, p. 310). Segundo Paul Ricouer, essa fórmula implica a constituição de uma justiça não violenta, e, de fato, ela foi muito festejada no campo político ao afirmarem que o trabalho da comissão assegurou uma transição pacífica do apartheid para o regime democrático (RICOUER, 2007). Porém, houve também muitas frustrações, sobretudo dos militantes do Congresso Nacional Africano. Maria Paula Araújo aponta para a opinião divergente do historiador Jonatan Grossman, para quem esse foco na relação vítima/algoz, revelação/perdão, seria despolitizador (ARAÚJO, 2012, p. 59). Grossman menciona que esteve presente em audiências da comissão e viu ativistas saírem desolados e desmoralizados:

[...] de fato, está em jogo algo mais importante do que a CVR equiparar alguns feitos dos resistentes com alguns feitos dos opressores e ser considerada "imparcial": a simpatia para com as vítimas está substituindo a valorização e o respeito pelos ativistas. O que as pessoas empreenderam juntas para fazer história está sendo colocado abaixo do que foi feito a elas enquanto indivíduos. Em outras palavras, os construtores coletivos da história estão sendo reduzidos a vítimas individuais. (GROSSMAN, 2000, p. 18).

Essa intersecção entre a ação política e a investigação historiográfica do passado e da memória remete às múltiplas tensões face às experiências e expectativas muito diversas dos grupos envolvidos.

Pretendemos, agora, situar o caso da transição e a memória no campo da historiografia brasileira. Para tanto, lembremos novamente do estudo de Rollemberg e sua problematização sobre uma certa memória coletiva construída, que faz uma dicotomia entre vítima e algoz, deixando de lado a base de apoio social do regime de 1964. Nesse campo, são ricas as contribuições e as advertências de Marcos Napolitano, para quem a resistência à ditadura tinha um caráter multifacetado de grupos e suas respectivas estratégias de luta política. No entanto, “criou-se uma memória, uma noção de espaço público de convergência de interesses e vontade de liberdade, que parece ter ficado perdida no tempo, reforçando a sensação de falta de um projeto político comum às correntes progressistas após o processo de abertura e redemocratização" (NAPOLITANO, 2004, p. 281). Com o fim do regime, essa perspectiva de mundo comum se diluiu ainda mais, com a fácil explicação da cooptação de alguns intelectuais e artistas críticos pelo sistema por serem seduzidos pelas suas benesses. Porém, vistas em seu conjunto, revelam os impasses e contradições da resistência cultural contra o

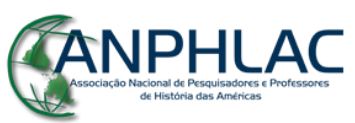

Revista Eletrônica da ANPHLAC, ISSN 1679-1061, №. 18, p. 56-86, jan./jul. 2015. http://revista.anphlac.org.br/ 
regime em meio a um processo dramático de modernização socioeconômica que tragava os melhores quadros de formação superior da classe média progressista para a indústria cultural e a burocracia da cultura, na mesma medida em que eram rompidos seus laços políticos com o conjunto das classes populares. Ao final, "este processo traumático teria sido compensado no plano da memória, recalcando as diferenças profundas e os conflitos entre os atores da resistência e marcando este conceito como tal sob o signo da experiência da partilha perdida" (NAPOLITANO, 2004, p. 282). Em outras palavras, precisamos levar em conta os riscos da construção da memória coletiva sobre o regime, que podem simplificar as complexidades do período e operar num processo de enquadramento da memória (POLLAK, 1989, p. 2).

Também aqui, no tratamento da memória, o vínculo das ditaduras do Cone-sul é evocado. Em especial o caso da transição argentina é constantemente levantado quando pensamos a nossa política da memória dos anos de chumbo. Carlos Fico (2012) aponta que, diferentemente dos hermanos, que buscaram analisar a fundo os traumas e as cicatrizes que a ditadura legou, a transição brasileira foi marcada por frustrações e impunidades. Aqui, o primeiro grande passo na direção do resgate de nossa memória da repressão foi dado com o lançamento do livro Brasil Nunca Mais (ARQUIDIOCESE DE SÃO PAULO, 1985), mas pouco foi realizado além disso. Fico aponta dois eventoschave que explicam a desilusão da passagem democrática brasileira: a campanha pela Anistia e a campanha das Diretas-Já. Esses dois momentos, cercados de esperanças e carregados de expectativas, foram frustrados pela capacidade que o sistema engendrou para promover uma transição "lenta e gradual" que o protegesse de eventuais represálias. Porém, avanços podem ser observados em pesquisas recentes. No plano da memória coletiva, certa historiografia, recorrentemente vinculada à História oral, tem desenvolvido metodologias para dar conta desse mecanismo complexo e fluido envolvendo narrativas literárias e históricas, assim como relações públicas e políticas do tempo presente. A escolha do tema do XI Encontro Nacional de História Oral, em 2012, intitulado "Memória, Democracia e Justiça", evidencia a tentativa de produzir um novo olhar, tanto no campo político quanto acadêmico, sobre as memórias da transição política no Brasil. Uma das principais obras relacionadas ao evento é o livro coletivo: Marcas da Memória: história oral da anistia no Brasil, organizado pelos professores

\section{GANPHLAC}


Antônio T. Montenegro, Carla S. Rodeghero e Maria Paula Araújo, que resulta de um projeto iniciado em 2008 de pesquisa por demanda social, vinculada à Comissão da Anistia do Ministério da Justiça (MONTENEGRO, 2012), produzido a partir de mais de cem entrevistas.

Por outro lado, devemos lembrar que o caso brasileiro é marcado por profundos déficits em seu processo transicional. A forma pactuada da transição brasileira e a persistência do poder político de inúmeros agentes e instituições do regime, assim como a longa cultura autoritária que marca nossa sociedade, tem levado a historiografia a discutir o silenciamento sobre esse passado recente. Exemplo disso é a grande resistência à atuação da Comissão Nacional da Verdade por certos setores da imprensa, militares e de empresários que estiveram vinculados ao regime ditatorial. Os militares recusaram-se a entregar documentos e cumprir determinações da CNV, órgão criado pela Presidência da República em maio de 2012, com a missão de "apurar e esclarecer, indicando as circunstâncias e a autoria, as graves violações de direitos humanos praticadas entre 1946 e 1988 (o período entre as duas últimas constituições democráticas brasileiras) com o objetivo de efetivar o direito à memória e a verdade histórica e promover a reconciliação nacional" (CNV, 2014). O órgão sofreu, ao longo dos 32 meses de sua existência, com inúmeras polêmicas sobre o papel de sua atuação e até mesmo com algumas tensões internas. O resultado final foi divulgado em 10 de dezembro de 2014, em relatório que procura detalhar as estruturas do Estado e as graves violações dos direitos humanos, a criação de órgãos e procedimentos de repressão política, a participação do Estado brasileiro em graves violações no exterior (incluindo as conexões internacionais para aliança repressiva no cone sul e a Operação Condor), os métodos e práticas das violações dos direitos humanos, as detenções ilegais e arbitrárias, a tortura, a violência sexual, a violência de gênero e a violência contra crianças e adolescentes, as execuções e mortes decorrentes da tortura, os desaparecimentos forçados, a atuação do Estado contra a Guerrilha do Araguaia (e suas violações contra camponeses e indígenas), as instituições e locais associados às violações, a autoria das violações e o papel do Judiciário. Apresentou, além disso, as violações de direitos humanos em face de atuação do Estado no meio militar, entre trabalhadores, camponeses, indígenas, homossexuais, dentro das igrejas cristãs e nas universidades, assim como apontou civis que colaboraram com a ditadura e, por fim, abordou a resistência da sociedade civil. Também fez uma série

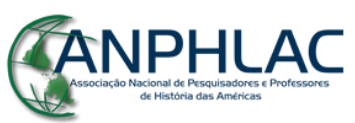

Revista Eletrônica da ANPHLAC, ISSN 1679-1061, №. 18, p. 56-86, jan./jul. 2015. http://revista.anphlac.org.br/ 
de recomendações que envolvem medidas institucionais, reformas constitucionais e legais, assim como medidas de seguimento das ações da $\mathrm{CNV}$, dentre elas: a revogação da Lei de Segurança Nacional, a desmilitarização das polícias militares estaduais, a extinção da Justiça Militar estadual, a exclusão de civis da jurisdição da Justiça Militar federal, a alteração da legislação processual penal para eliminação da figura do auto de resistência à prisão, a introdução da audiência de custódia para prevenção da prática da tortura e de prisão ilegal, o prosseguimento e fortalecimento da política de localização e abertura dos arquivos da ditadura militar, e o estabelecimento de órgão permanente com atribuição de dar seguimento às ações e recomendações da CNV.

Evidentemente, tal processo é tenso e problemático; a CNV foi criticada à direita, por ser considerada revanchista e unilateral, e pela academia, por ter deixado de fora "os casos de perseguição de cidadãos comuns, aqueles que não eram militantes de esquerda, mas que também foram vítimas da extensa rede de espionagem instalada no Brasil", como os servidores que perderam o emprego ou tiveram a carreira na administração pública comprometida por alguma desconfiança dos órgãos de repressão. Para Carlos Fico, "ao incluir essas pessoas comuns no rol das vítimas, a sociedade brasileira perceberia o dano causado pela ditadura a todos, e não apenas àqueles que lutaram contra o regime" (MARTINS, 2014). De todo modo, ainda que a comissão não tenha o poder de julgamento nem de punição, suas descobertas poderão ser arroladas em

processos e esforços jurídicos contra os agentes do regime e tratam de um reconhecimento oficial do Estado brasileiro de que as práticas de tortura e as violações dos direitos humanos constituíram-se enquanto política de Estado durante a ditadura. Por outro lado, seu trabalho foi importante por fomentar a criação de quase uma centena de comissões da verdade em diversos âmbitos estaduais, municipais, em universidades e órgãos públicos, assim como da Ordem dos Advogados do Brasil - OAB - em plano nacional e estaduais. Ainda que a Comissão da Verdade exponha os riscos de entronizações de histórias oficiais ou uma romantização de atores e grupos, ela certamente servirá para iluminar passagens ainda obscuras de nossa história, revelando, quem sabe, uma cicatriz ainda maior do que aquela que já temos. Mas então, com uma imagem mais realística de nossas feridas, possamos talvez iniciar o processo de cura e alcançar, de uma vez, a catarse democrática.

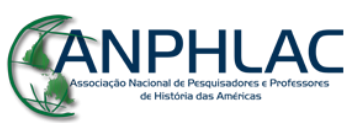

Revista Eletrônica da ANPHLAC, ISSN 1679-1061, №. 18, p. 56-86, jan./jul. 2015. http://revista.anphlac.org.br/ 


\section{GANPHLAC}

Revista Eletrônica da ANPHLAC, ISSN 1679-1061, №. 18, p. 56-86, jan./jul. 2015.

http://revista.anphlac.org.br/ 


\section{Referências bibliográficas:}

ABREU, Alzira Alves de (org.). A democratização no Brasil: atores e contextos. Rio de Janeiro: FGV, 2006.

AGAMBEN, Giorgio. Estado de exceção: homo sacer II, 2 ed. São Paulo: Boitempo, 2004.

AGUILA, Gabriela. Testemunhos e vizinhos: a ditadura na Grande Rosário (Argentina). In: QUADRAT, Samantha Viz; ROLLEMBERG, Denise. A construção social dos regimes autoritários. Rio de Janeiro: Civilização Brasileira, 2010, p. 597-614.

ALVES, Maria Helena Moreira. Estado e oposição (1964-1984). Petrópolis: Edusc, 2005.

ARAÚJO, Maria Paula Nascimento. A utopia fragmentada: as novas esquerdas no Brasil e no mundo na década de 1970. Rio de Janeiro: FGV, 2000.

ARQUIDIOCESE DE SÃO PAULO. Brasil Nunca Mais. Petrópolis: Vozes, 1985.

ASSOCIAÇÃO de Docentes da Universidade de São Paulo, O livro negro da Usp: o controle ideológico da universidade. 3. ed. São Paulo: Brasiliense, 1979.

BORGES FILHO, N. Sobre o sagrado e o profano. Civil e militares na política brasileira. Florianópolis: Letras contemporâneas, s.d.

A Doutrina de Segurança Nacional e os governos militares. In: FERREIRA, Jorge. (org.) O tempo da ditadura: regime militar e movimentos sociais em fins do século XX. Rio de Janeiro: Civilização Brasileira, 2003, p. 13-43.

BOSCHI, Renato Raul. Elites industriais e democracia: hegemonia e mudança política no Brasil. Rio de Janeiro: Graal, 1979.

CALVEIRO, Pilar. Poder e desaparecimento. São Paulo: Boitempo, 2013.

CASTRO, Celso, D’ARAUJO, Maria Celina (org.). Dossiê Geisel. Rijo de Janeiro, FGV, 2002.

CHIRIO, Maud __. Le Pouvoir em um Mot: les militaires brésiliens et la 'révolution' du 31 mars 1964. In: Nuevos Mundos, Mundos Nuevos. Jan. 2007. < http://nuevomundo.revues.org/3887> [consultado em 06 mai. 2014].

A Política nos Quarteis: revoltas e protestos de oficiais na ditadura militar brasileira. Rio de Janeiro: Zahar, 2012.

\section{GANPHLAC}

Revista Eletrônica da ANPHLAC, ISSN 1679-1061, №. 18, p. 56-86, jan./jul. 2015.

http://revista.anphlac.org.br/ 
CNV - Comissão Nacional da Verdade. Relatório Final. 3 vol. Brasília: CNV, 2014. < http://www.cnv.gov.br/index.php?option=com_content\&view=article\&id=571> [consultado em 11 jan. 2015].

CODATO, Adriano Nervo. Uma história política da transição brasileira: da ditadura militar à democracia. Revista de Sociologia Política, Curitiba, n. 25, Nov. 2005, 1-24.

O golpe de 1964 e o regime de 1968: aspectos conjunturais e variáveis históricas. História Questões e Debates. Curitiba, v. 40, p. 7-30, 2004.

COICAUD, Jean-Marc. L'introuvable démocratie autoritaire: les dictatures du Cône sud - Uruguay, Chili, Argentine (1973-1982). Paris: L'Harmattan, 1996.

D'ARAÚJO, Maria Celina de; SOARES, Gláucio. A Memória Militar sobre o Golpe; A Memória Militar sobre a Repressão; A Memória Militar sobre a Abertura. Rio de Janeiro: Relume-Dumará, 1994-5.

DINGES, John. Os anos do Condor - uma década de terrorismo internacional no Cone Sul. São Paulo: Cia das Letras, 2005.

DREIFUSS, René Armand. 1964: a conquista do Estado. Petrópolis: Vozes, 1981.

ELSTER, Jon. Closing the book: transitional justice in historical perspective. Cambridge: Cambridge Universtity, 2004.

FERREIRA, Jorge; GOMES, Angela de Castro. 1964: o golpe que derrubou um presidente, pôs fim ao regime democrático e instituiu a ditadura no Brasil. Rio de Janeiro: Civilização Brasileira, 2014.

FERREIRA, Jorge. O nome e a coisa: o populismo na política brasileira. (org.) $O$ populismo e a sua história: debate e crítica. Rio de Janeiro: Civilização Brasileira, 2001. p. $59-125$.

Crises da República: 1954, 1955 e 1961. In: FERREIRA, Jorge; DELGADO, Lucilia de Almeida Neves (org.). O Brasil republicano: o tempo da experiência democrática da democratização de 1945 ao golpe civil-militar de 1964. Rio de Janeiro: Civilização Brasileira, 2003, p. 336-339.

FICO, Carlos. Brasil: A transição inconclusa. In: FICO, Carlos; ARAÚJO, Maria Paulo; GRIN, Monica (org.). Violência na história - memória, trauma, reparação. Rio de Janeiro: Ponteio, 2012.

. Versões e Controvérsias sobre 1964 e a ditadura militar. In: Revista Brasileira de História. Vol, 24, No. 47. São Paulo, 2004, p. 29-60.

Além do golpe: versões e controvérsias sobre 1964 e a ditadura. Rio de Janeiro: Record, 2004.

\section{CANPHLAC}


O Grande Irmão: da operação Brother Sam aos anos de Chumbo. O governo dos Estados Unidos e a ditadura militar brasileira. Rio de Janeiro: Civilização Brasileira, 2008.

FINCH, Henry. Uruguay - 1930c - 1990. In: BETHELL, Leslie (org.). História de América Latina. Tomo 15. Barcelona: Editorial Crítica, 2002, p. 156-286.

FOLHA DE SÃO PAULO. Editorial - Limites à Chávez. 17 fev. 2009. < http://www1.folha.uol.com.br/fsp/opiniao/fz1702200901.htm> [acessado em 06 mai. 2014].

GREEN, James. Apesar de vocês. São Paulo: Cia das Letras, 2005.

GREEN, James; QUINALHA, Renan. Ditadura e homossexualidades: repressão, resistência e a busca da verdade. São Paulo: EdUFSCAR, 2014.

HILB, Claudia. Usos del Pasado - Qué hacemos hoy com los setenta. Buenos Aires: Siglo Veintiuno, 2013.

HUNTINGTON, Samuel. The Third Wave. Norman: Oklahoma, 1993.

The Soldier and the State: the theory and politics of civil-military relations. New York: Random House, 1964.

JOFFILY, Mariana. No centro da engrenagem: os interrogatórios na Operação Bandeirante e no DOI-CODI de São Paulo (1969-1975). Rio de Janeiro/São Paulo: Arquivo Nacional/Edusp, 2012.

LEWIS, Paul. Paraguay - 1930c - 1990. In: BETHELL, Leslie (org.). História de América Latina. Tomo 15. Barcelona: Editorial Crítica, 2002, p. 187-218.

LINZ, Juan J.; STEPAN, Alfred. A transição e a consolidação da democracia: a experiência do sul da Europa e da América do sul. SP: Paz e Terra, 1999.

LINZ, Juan. The future of an authoritarian situation or the institutionalization of an authoritarian regime: the case of Brasil. In: STEPAN, Alfred (org.). Authoritarian Brazil: origins, policies and future. New York: Yale, 1973.

Totalitarian and authoritarian regimes. Boulder: Rienner, 2000.

LIPSET, Seymour. Some Social Requisites from Democracy: Economic Development and Political Legitimacy. In: The American Political Science Review. No. 53. 1959, p. 69-105.

LOPES, Ernesto. Ni la ceniza, ni la Gloria: actores, sistema politico y cuestion militar en los años de Alfonsin. Quilmez: Universidad Nacional de Quilmes, 1994.

\section{GANPHLAC}

Revista Eletrônica da ANPHLAC, ISSN 1679-1061, №. 18, p. 56-86, jan./jul. 2015.

http://revista.anphlac.org.br/ 
MAINWARING, Scott; PÉREZ-LIÑÁN, Aníbal. Democracies and Dictatorships in Latin America: Emergence, Survival, Fall. Cambridge: Cambridge Univ. Press, 2014.

MARTINS FILHO, João Roberto. O palácio e a caserna: a dinâmica militar das crises políticas na ditadura (1964-1969). São Paulo: EDUFSCar, 1995.

MARTINS, Rodrigo. Especialistas criticam foco excessivo da CNV em casos já sabidos. Carta Capital. 12.12.2014. Pagina inicial/sociedade. Disponível em: <http://www.cartacapital.com.br/sociedade/especialistas-criticam-foco-excessivo-da-cnv-em-casosja-sabidos-1125.html > . Acesso em 15.01.2015.

McSHERRY, J. Patrice. Tracking the Origins of a State Terror Network - Operation Condor. In: Latin American Perspectives. Iss. 122, vol. 29, No. 1. Jan. 2002, p. 38-60.

MERGEL, Thomas. Kulturgeschichte der Politik. In: Docupedia-Zeitgeschichte. 11 fev. 2010. < https://docupedia.de/zg/Kulturgeschichte_der_Politik?oldid=75525>, visitado em 17 out. 2014.

MEZAROBBA, Glenda. O que é justiça de transição? Uma análise do conceito a partir do caso brasileiro. In: SOARES, Inês V. P (et all). Memória e verdade: a justiça de transição no Estado Democrático Brasileiro. BH: Forum, 2009, p. 37-54.

MONTENEGRO, Antônio; ARAUJO, Maria Paula Nascimento; RODEGHERO, Carla S. Marcas da memória: história oral a anistia no brasil. Recife: UFPE, 2012.

MORAES, João C. K. Quartim de. Liberalismo e ditadura no cone sul. Campinas: Unicamp, 2001.

MOTTA, Rodrigo Patto Sá. Jango e o golpe de 1964 na caricatura. Rio de Janeiro: Jorge Zahar, 2006.

A cultura política comunista - alguns apontamentos. In: MOTTA, Rodrigo Patto Sá; NAPOLITANO, Marcos (org.). Comunistas brasileiros- cultura política e produção cultural. Belo Horizonte: EdUFMG, 2013.

. As Universidades e o Regime Militar. Rio de Janeiro: Zahar, 2014.

Em guarda contra o perigo vermelho. São Paulo: Perspectiva, 2002.

NAPOLITANO, Marcos. 1964 - História do regime militar brasileiro. São Paulo: Contexto, 2014.

. O Golpe de 1964 e o Regime Militar Brasileiro - Apontamentos para uma Revisão Historiográfica. In: Contemporanea - Historia y problemas del siglo XX. Vol. 2, Ano 2, jun.- dez. 2011, p. 209-217.

\section{GANPHLAC}

Revista Eletrônica da ANPHLAC, ISSN 1679-1061, №. 18, p. 56-86, jan./jul. 2015.

http://revista.anphlac.org.br/ 
. Seguindo a canção - Engajamento político e indústria cultural na MPB (19591969). São Paulo: Annablume, 2001.

O 'tesouro perdido': a resistência no campo da cultura (Brasil 1969-1976). In: DUARTE, André (org.). A banalização da violência: atualidade do pensamento de Hannah Arendt. Rio de Janeiro: Relume Dumará, 2004, p. 275-283.

O'DONNELL, Guillermo. Modernization and bureaucratic authoritarianism: studies in South american politics. Berkeley: institute of international Studies, Univesity of California, 1973.

. Análise do autoritarismo burocrático. Rio de Janeiro: Paz e terra, 1990.

Reflexões sobre os Estados burocrático-autoritários. São Paulo: Vértice, 1987.

PADRÓS, Enrique. Enterrados vivos: a prisão política na ditadura uruguaia e o caso dos reféns. In: Espaço Plural. Ano XIII, No. 27, jul-dez 2012, p. 13-38.

Como el Uruguay no hay... Terror de Estado e Segurança Nacional. Tese de doutorado apresentada junto à UFRGS. Porto Alegre, 2005.

PEREIRA, Anthony W. Ditadura e repressão: o autoritarismo e o estado de direito no Brasil, no Chile e na Argentina. São Paulo: Paz e Terra, 2010.

PINHEIRO, Milton (org.). Ditadura: O que resta da transição. São Paulo: Boitempo, 2014.

POLLAK, Michael. Memória, esquecimento, silêncio. Estudos históricos, RJ, vol 2, n. 3, 1989, p. 3-15.

QUADRAT, Samantha Viz O Brasil sob a asa sombria do Condor. In: MARTINS FILHO, João Roberto (org.). O Golpe de 1964 e o Regime Militar. São Carlos: Edufscar, 2006, p. 161-181.

A Oposição Juvenil à Unidade Popular. In: QUADRAT, Samantha Viz; ROLLEMBERG, Denise. A construção social dos regimes autoritários. Rio de Janeiro: Civilização Brasileira, 2010, p. 521-562.

REIS, Daniel Aarão. Ditadura e democracia no Brasil. Do golpe de 1964 à Constituição de 1988. Rio de Janeiro: Zahar, 2014.

RICOUER, Paul. A memória, a história, o esquecimento. SP: Unicamp, 2007.

RIDENTI, Marcelo. Resistência e Mistificação da Resistência Armada contra a Ditadura: armadilhas para pesquisadores. In: Seminário 40 Anos do Golpe de 1964. Rio de Janeiro: 7Letras, 2004.

\section{GANPHLAC}

Revista Eletrônica da ANPHLAC, ISSN 1679-1061, №. 18, p. 56-86, jan./jul. 2015.

http://revista.anphlac.org.br/ 
RIDENTI, Marcelo; Reis, Daniel Aarão, Motta, Rodrigo Patto Sá (orgs.). A ditadura que mudou o Brasil: 50 anos do golpe de 1964. Rio de Janeiro: Zahar, 2014.

ROLLEMBERG, Denise. Esquerdas revolucionárias e luta armada. In: FERREIRA, J.; DELGADO, L. de A. N. (Orgs.) O Brasil republicano - o tempo da ditadura: regime militar e movimento sociais em finas do século XX. Rio de Janeiro: Civilização Brasileira, 2003, p. 43-91.

As trincheiras da memória: A Associação Brasileira de Imprensa e a Ditadura (1964-1974). In: QUADRAT, Samantha Viz; ROLLEMBERG, Denise. A construção social dos regimes autoritários. Rio de Janeiro: Civilização Brasileira, 2010, p. 97-144.

ROSANVALLON, Pierre. Por uma história conceitual do político (nota de trabalho). Revista Brasileira de História. São Paulo, v. 15, n. 30, p. 9-22, 1995.

SANTOS, Wanderley Guilherme dos. O Cálculo do Conflito: Estabilidade e Crise na Política Brasileira. Belo Horizonte: EDUFMG, 2003.

SARLO, Beatriz. Tempo passado. Cultura da memória e guinada subjetiva. São Paulo: Companhia das Letras, 2007.

SILVA, Francisco C. Teixeira. Crise da ditadura e o processo de abertura política no Brasil: 1974-1985. In: FERREIRA, J. (org.) O tempo da ditadura: regime militar e movimentos sociais em fins do século XX. RJ: Civilização Brasileira, 2003.

SKIDMORE, Thomas. Brasil: de Castelo a Tancredo (1964-1985). 7. ed. RJ: Paz e Terra, 1988.

Uma história do Brasil. RJ: Paz e Terra, 1994.

STEPAN, Alfred. The Military in Politics: Changing Patterns in Brazil. Princeton: Princeton Univ. Press, 1971.

Os militares da abertura à Nova república. 4 ed. RJ: Paz e terra, 1986.

Authoritarian Brazil: origins, policies, and future. New Haven e Londres: Yale University Press, 1973.

Estado, corporativismo e autoritarismo. Rio de Janeiro: Paz e Terra, 1980.

Os militares na política: as mudanças de padrões na vida brasileira. Rio de Janeiro: Artenova, 1975.

TEITEL, Ruti G. Transitional justice genealogy. Harvar Human Rights Journal, Cambridge (MA), v. 16, Spring 2003.

\section{GANPHLAC}

Revista Eletrônica da ANPHLAC, ISSN 1679-1061, №. 18, p. 56-86, jan./jul. 2015.

http://revista.anphlac.org.br/ 
TELES, Edson; SANTOS, Cecília Macdonwell; TELES, Janaina de Almeida (orgs.) Desarquivando a ditadura: memória e justiça no Brasil; v1 e 2. São Paulo: Aderaldo \& Hothschild Editores, 2009.

TELES, Janaína de Almeida. Ditadura e repressão no Brasil e na Argentina: paralelos e distinções. Introdução a CALVEIRO, Pilar. Poder e Desaparecimento. São Paulo: Boitempo, 2013, p. 7-18.

TOLEDO, Caio Navarro. 1964: Golpismo e democracia. As falácias do revisionismo. Revista Crítica Marxista, Campinas, v. 19, 2004. 27-49.

VILLA, Marco Antonio. Ditadura à brasileira. São Paulo: Leya, 2014.

ZAVERUCHA, Jorge. Relações civis militares; o legado autoritário da Constituição de 1988. In: SAFATLE, Vladimir; TELLES, Edson. (org.). O que resta da ditadura: a exceção brasileira. SP: Boitempo, 2010, p. 41-77. 